
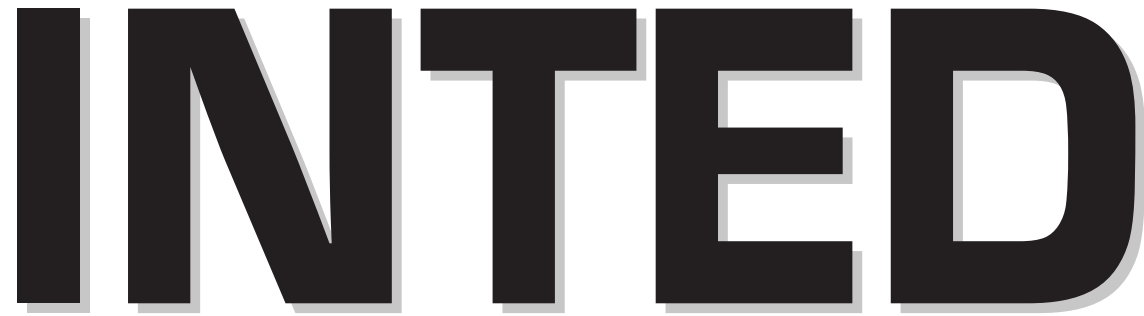

\section{7}

11th International

Technology, Education and

Development Conference

6-8 March, 2017

Valencia (Spain)

\section{CONFERENCE PROCEEDINGS}


Published by

IATED Academy

iated.org

INTED2017 Proceedings

11th International Technology, Education and Development Conference

March 6th-8th, 2017 - Valencia, Spain

\section{Edited by}

L. Gómez Chova, A. López Martínez, I. Candel Torres

IATED Academy

ISBN: 978-84-617-8491-2

ISSN: $2340-1079$

Depósito Legal: V-369-2017

Book cover designed by

J.L. Bernat

All rights reserved. Copyright (C) 2017, IATED

The papers published in these proceedings reflect the views only of the authors. The publisher cannot be held responsible for the validity or use of the information therein contained. 


\title{
GO WHERE THE STUDENTS ARE: GROUPS IN FACEBOOK TO IMPROVE COMMUNICATION BETWEEN STUDENTS AND EDUCATORS
}

\author{
A. Najera', J. Gonzalez-Rubio', R. Ramirez-Vazquez ${ }^{1}$, C. P. Suarez-Rodriguez ${ }^{2}$, \\ P. Gomez ${ }^{1}$, A. Beléndez ${ }^{3}$, F.J. Escobar-Rabadan ${ }^{4}$, E. Arribas ${ }^{1}$, R. Reolid ${ }^{1}$ \\ ${ }^{1}$ University of Castilla - La Mancha (SPAIN) \\ ${ }^{2}$ University of San Luis Potosi (MEXICO) \\ ${ }^{3}$ University of Alicante (SPAIN) \\ ${ }^{4}$ Health Center Zona IV. SESCAM (SPAIN)
}

\begin{abstract}
With the arrival of social media, medical students, future healthcare professionals, not only need to be aware of professionalism in their face-to-face interactions but also in the new virtual environments. Use of social networking by medical students is increasing, and some students lack awareness of consequences arising from the crossing of social networking and medicine. In this context, the use of Facebook could develop medical education beyond the restrictions of the classroom, and be the connection between informal and formal learning, engaging students with educational content outside the classroom. Moreover, social media can be also used in health care training to improve communication between students and educators, patient communication, public health programs or research.
\end{abstract}

The aim of this study was to assess the interest and participation of students and educators of the Faculty of Medicine of the University of Castilla-La Mancha (Spain) in a closed and private group in Facebook.

The group was created in September 2011 and it already has 939 users between administrative staff, teachers and students. There were no rules more than terms of use of Facebook, but it is recommendable that posts might be related to Health and Research in Medical Sciences.

We analysed its use during the course 2015-16 through which there were a total of 563 publications, most of them done by students $(344 ; 61 \%)$ rather than the faculty and the staff $(219 ; 39 \%)$. A total of 9,375 impressions, comments and shares were also registered. We classify publications between three mayor themes: those related to learning (181), scientific advances and science spreading (242), and other (140). Students shared more contents related to learning process (139) rather than scientific advances (94) and others (111), while teachers shared 148, 42 and 29 respectively. We also analysed the number or impressions to post 583 comments, 130 shares, and a total of 8662 impressions ("likes").

Students greatly appreciate the group use by teachers, but only a few have an account in social networks. In general, the posts that raise more interest were those related to science. We perform an opinion survey in the group: a total of 97 users answer the survey, 96 indicated that the group was useful or very useful and that they were very satisfied; only one user indicates that was fairly satisfied.

The group facilitates communication between students and teachers, approaching each other, the group helped to create "community". These groups, where informal themes can be shared and discussed, could help to acquire a number of very interesting and characteristic competitions of the time we live in extracurricular.

Keywords: Social media, Facebook, medical education, e-learning; innovations in medical education.

\section{INTRODUCTION}

The use of social media has become popular in the last years, modifying, in many cases, our habits of life but not only in the personal scope but also in the professional and educative [1]-[5]. Closed groups specialized in higher education are already frequent. The use of these new platforms to exchange, share and communicate ideas and knowledge among students, in particular Medicine, open new possibilities in student-teacher relations [6]-[17]. 
Students are very familiar with the use of social networks, access daily and from multiple devices. These sites are a place where the communication is close and horizontal, as opposed to the typical decent vertical model in which the student-teacher relationship has been based on lectures and reading books, where interaction was limited. Without questioning the importance of this relationship, the arrival of new teaching models that are based on self-learning, the inclusion of new technologies and new communication spaces such as social networks, the teaching model should not remain unaware of these changes and assume them in order to exploit their potential [10], [18]-[21].

The learning of medical students includes a number of aspects that deserve more attention. The use of social networks by health professionals when it is time to publish or share certain information may not be the most appropriate, sometimes surpassing the thin line that separates your personal life from the professional [7], [22]-[26].

Acting in social networks in the right way, can be a crucial aspect in the education and training of future professionals. And to include this competence in your training plan, the use of educational groups on Facebook in which students and teachers can interact and share even non-professional information can be an exceptional tool to prevent future misuse [27]-[29].

The objective of this study was to follow up and describe a private group on Facebook during a full academic year in order to evaluate the usefulness and satisfaction of the students of the degree of Medicine of the Faculty of Albacete of the University of Castilla - La Mancha.

\section{METHODOLOGY}

Since 2011, the Faculty of Medicine in Albacete has a private group on Facebook that can only access students, teachers and staff of the Faculty. Currently, January 2017, the group has 1050 users of which only 14 are teachers or management staff. Each year, new students are invited to join this virtual community in which there are no rules, rules or limitations in publications, except that the topics published must be related to the Centre, both from the point of view of teaching and of university life at the centre.

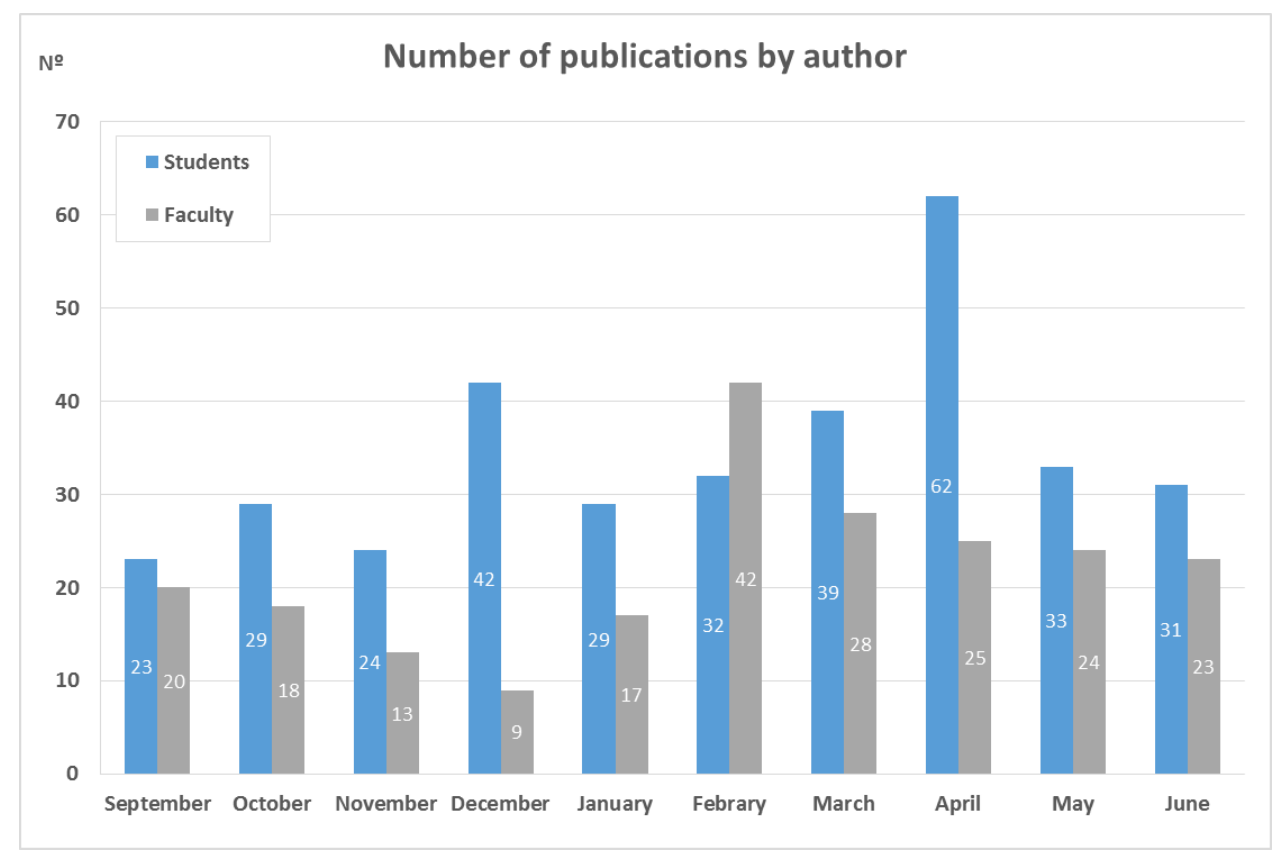

Fig 1. Temporal distribution of publications by author.

During the 2015-16 academic year (from September to June), the group's publications and comments were tracked. In this way the publications were counted and classified in three large blocks: related to teaching, science dissemination or extension of knowledge and others. This last section includes any publication that cannot be classified in the previous blocks, as it could be that a student has lost a book or the organization of a party. The publications were also classified according to their authorship: students, professionals of the faculty, both teachers and administration. 
Finally, in October 2016, a very simple group use satisfaction survey of a single question was conducted in the group.

\section{RESULTS}

\subsection{Total publications}

In total, 563 publications were registered, of which 344 were carried out by students $(61 \%)$ and 219 by teachers (39\%). Figure 1 shows the number of publications per month and authorship being April the month with the highest number of publications reaching the 87 publications in a single month, which represents 2.8 daily publications.

Of the total number of publications, 242 were news, outreach links or complementary information to the training, accounting for $42.9 \%$ of the total. Publications related to teaching, announcements, coordination or teaching incidents accounted for $32.1 \%$, in total 181 , while the rest of publications, $24.9 \%$, are included in the "other" category. Figure 2 shows the number of publications by type and month, highlighting April with the maximum registration of 52 publications of type teaching and February with the maximum registration of publications of disclosure.

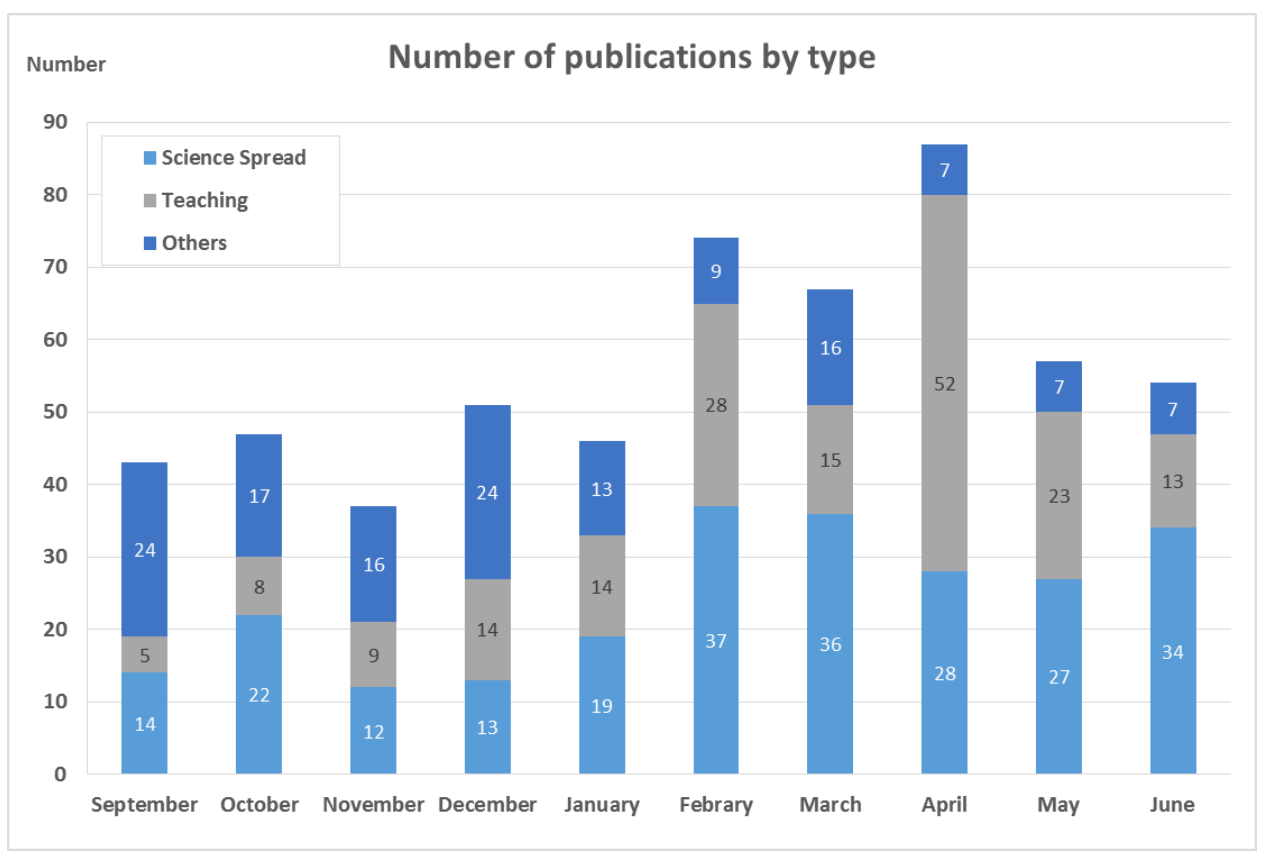

Fig 2. Temporal distribution of publications by type of publication.

\subsection{Publications classified by type and authorship}

The following is the number of publications by type, authorship and month. Thus, Figure 3 shows the publications made by the students depending on the type. Of the 344 publications of students in the group, 94 were science dissemination, 139 related to the centre or teaching and 111 in the "others" block. The month in which there was less activity on the part of the students was November with only 24 publications. On the other hand, April registered a high activity reaching the 62 publications of students in a single month, being 43 related to teaching.

Figure 4 shows the same data but for publications made by the faculty staff, in total 219 being 148 of disclosure, 42 of teaching and 29 in the block "other". In this case, the month with the lowest number of publications was December, when only 9 were registered, all of them being disseminated. The maximum activity was registered in February with a total of 42 publications ( 29 of disclosure, 10 of teaching and 3 of others, being $18.3 \%$ of the total in a single month). 


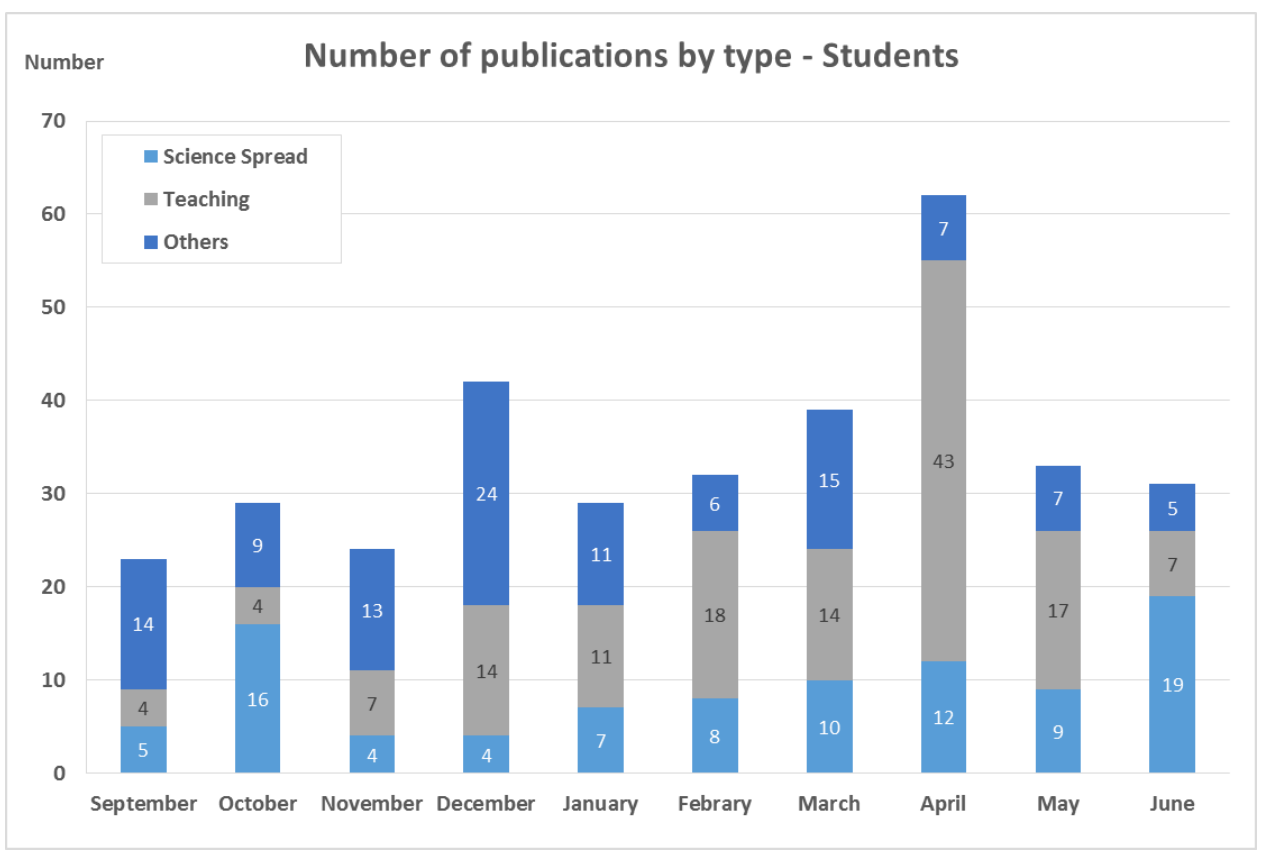

Fig 3. Temporal distribution of publications made by the students classified by type.

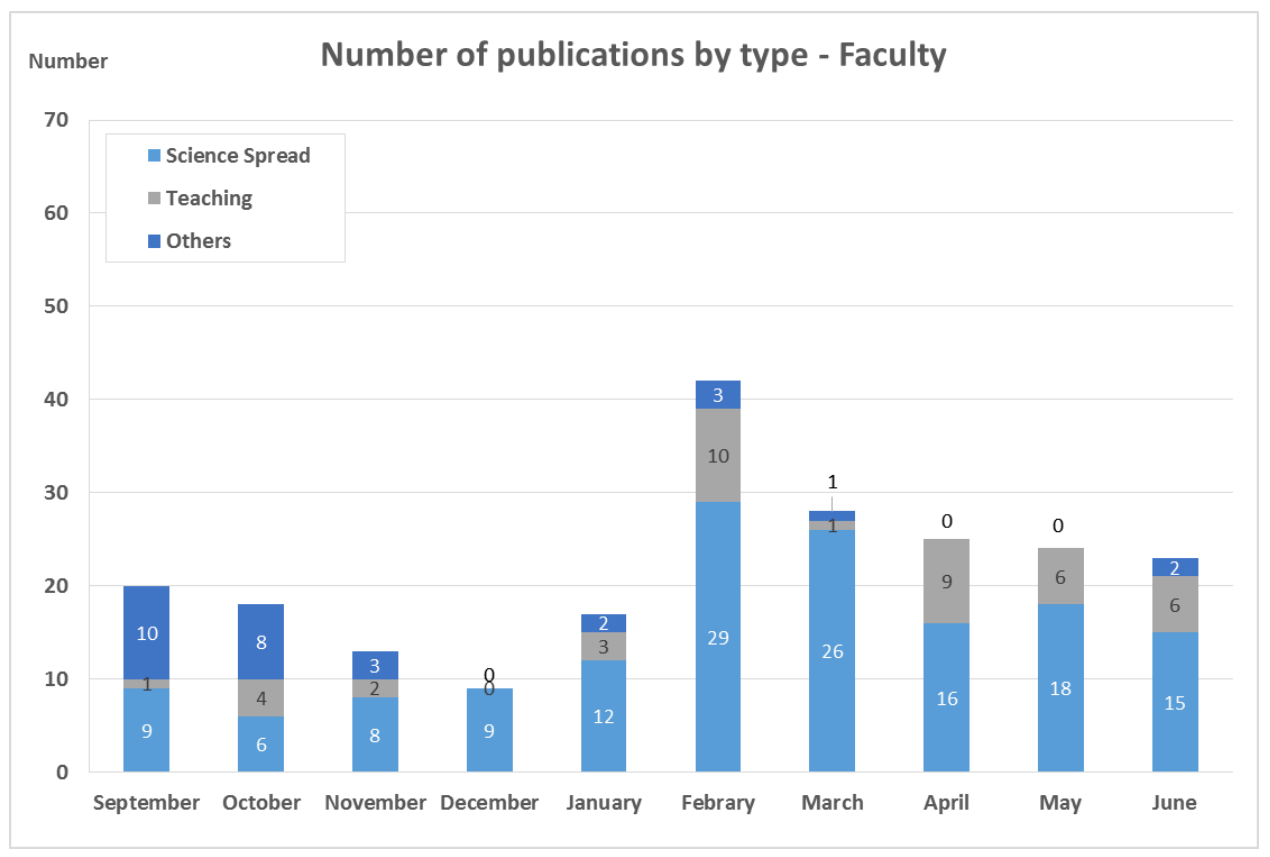

Fig 4. Temporal distribution of publications made by the faculty classified by type.

\subsection{Generated responses and impressions}

A publication in the group can generate or receive responses or impressions. These impressions are the well-known "like" in all its aspects (it makes me angry, it makes me sad, etc.). In total, in the period analysed, a total of 9375 impressions and comments were generated. The comments accounted for $6.2 \%$ with 583 distributed so that 124 were made in science dissemination publications, 275 in response to teaching publications and 184 to the rest. The number of impressions generated was $8662(92.4 \%)$ distributed in 2812 in publicity publications, 3443 in content of teaching and 2407 in the rest. Figure 5 shows these data, as well as the number of times the different publications were shared. 


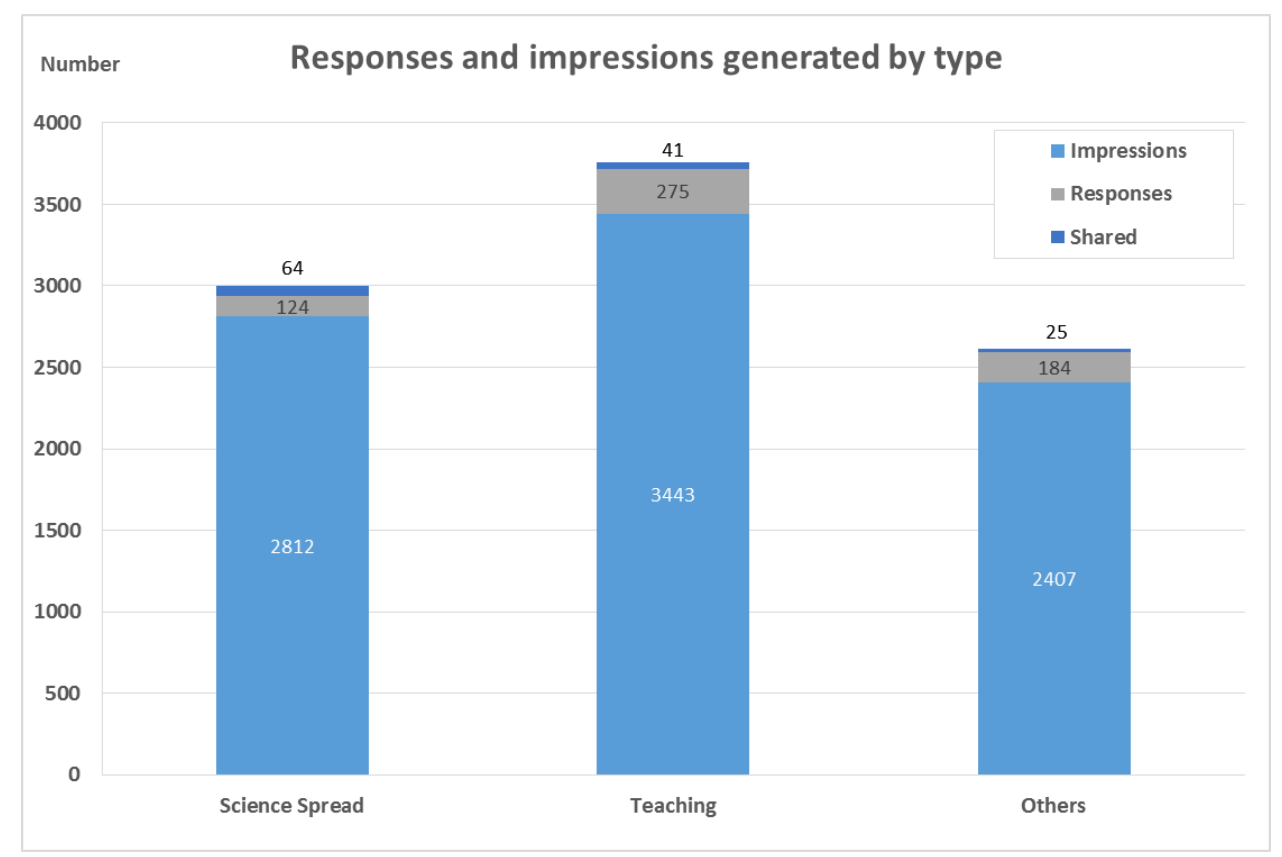

Fig 5. Responses and impressions generated in the group classified by type of publication.

In total, each publication related to teaching generated an average of 19.0 impressions and 1.5 responses. Outreach publications produced 11.6 impressions on average and 0.5 responses versus 17.2 impressions generated by "other" block publications and 0.2 responses.

\subsection{Evaluation of satisfaction}

In October 2016, a satisfaction survey was published in the group on Facebook. A total of 116 students from the group who accounted for $12.6 \%$ of the students at that time answered. 91 students said the group was very good, 23 felt they were helpful Only 1 student indicated that the group did not seem at all useful.

\section{DISCUSSION}

The total of 563 publications in the period studied, supposes an average of 1.8 daily, counting weekends. If we perform the same calculation with the 9375 impressions and responses recorded, the daily average is 30.2 . In total, 32.1 publications or responses and impressions per day have been registered in the group, which gives an idea of the high-recorded activity. If we join this result to the fact that $98.3 \%$ of the students who answered the question of satisfaction and usefulness of the group, we think that this new space not only registers an important activity but the degree of reception by the students is high.

It should be noted that many students do not want to make visible their activity in the group and mark an impression or write a comment, although when asked in class for a publication, it is normal that practically all have seen, but few have left an impression. Their general comment is that they prefer to see without being seen and accessing several times to the day to the group.

However, although the activity of teachers has been high, few have a Facebook account and fewer who have requested access to the group. In general the main comment among fellow teachers is the fear of losing privacy by participating in a group and exposing their profile to the students. It would therefore be very interesting that more teachers learn to manage the privacy of their profiles in social networks and take advantage of a space of communication that generates a large number of interactions between students and teachers that, probably in other circumstances, would be very difficult [4].

The large number of publicity publications made by students and teachers are an additional material to the teaching that comes directly to the profiles of the students, in an environment outside the teaching and more colloquial, generating in some cases, debate, questions and exchange of ideas [7]. The exchange of medical information and web pages with medical content and discussion also fosters the 
development of critical thinking and collaboration [5]. A group in which both students and teachers interact in the same place is interesting to improve the type of information that is accessed and the sources that are used by both agents [30].

\section{CONCLUSIONS}

The teaching group of the Faculty of Medicine of Albacete registers a high activity, mainly by the students. The group is perceived as useful or very useful by the students being a meeting place for the exchange of teaching and science dissemination issues with links and complementary material for their training.

\section{ACKNOWLEDGEMENTS}

To all the students and faculty who participated in this work.

\section{REFERENCES}

[1] K. Collins, D. Shiffman, and J. Rock, "How Are Scientists Using Social Media in the Workplace?," PloS One, vol. 11, no. 10, p. e0162680, 2016.

[2] T. A. Pempek, Y. A. Yermolayeva, and S. L. Calvert, "College students' social networking experiences on Facebook," J. Appl. Dev. Psychol., vol. 30, no. 3, pp. 227-238, Jun. 2009.

[3] A. M. Kaplan and M. Haenlein, "Users of the world, unite! The challenges and opportunities of Social Media," Bus. Horiz., vol. 53, no. 1, pp. 59-68, Feb. 2010.

[4] A. Mostaghimi and B. H. Crotty, "Professionalism in the Digital Age," Ann. Intern. Med., vol. 154, no. 8, p. 560, Apr. 2011.

[5] H. Alsobayel, "Use of Social Media for Professional Development by Health Care Professionals: A Cross-Sectional Web-Based Survey," JMIR Med. Educ., vol. 2, no. 2, p. e15, Sep. 2016.

[6] A. Acquisti and R. Gross, "Imagined communities: Awareness, information sharing, and privacy on the facebook," in Privacy Enhancing Technologies, vol. 4258, G. Danezis and P. Golle, Eds. Berlin: Springer-Verlag Berlin, 2006, pp. 36-58.

[7] N. Park, K. F. Kee, and S. Valenzuela, "Being Immersed in Social Networking Environment: Facebook Groups, Uses and Gratifications, and Social Outcomes," Cyberpsychol. Behav., vol. 12, no. 6, pp. 729-733, Dec. 2009.

[8] S. Zhao, S. Grasmuck, and J. Martin, "Identity construction on Facebook: Digital empowerment in anchored relationships," Comput. Hum. Behav., vol. 24, no. 5, pp. 1816-1836, Sep. 2008.

[9] E. A. Gage-Bouchard, S. LaValley, M. Mollica, and L. K. Beaupin, "Communication and Exchange of Specialized Health-Related Support Among People With Experiential Similarity on Facebook," Health Commun., pp. 1-8, Aug. 2016.

[10] S. El Bialy and A. Jalali, "Go Where the Students Are: A Comparison of the Use of Social Networking Sites Between Medical Students and Medical Educators," JMIR Med. Educ., vol. 1, no. 2, p. e7, Sep. 2015.

[11] A. Ali, "Medical students' use of Facebook for educational purposes," Perspect. Med. Educ., vol. 5, no. 3, pp. 163-169, Jun. 2016.

[12] J. D. Pickering and S. R. Bickerdike, "Medical student use of Facebook to support preparation for anatomy assessments," Anat. Sci. Educ., Nov. 2016.

[13] N. M. Alotaibi et al., "Social Media for Academic Neurosurgical Programs: The University of Toronto Experience," World Neurosurg., vol. 93, pp. 449-457, Sep. 2016.

[14] E. R. Ranschaert, P. M. A. Van Ooijen, G. B. McGinty, and P. M. Parizel, "Radiologists' Usage of Social Media: Results of the RANSOM Survey," J. Digit. Imaging, vol. 29, no. 4, pp. 443-449, Aug. 2016. 
[15] S. Y. Guraya, "The Usage of Social Networking Sites by Medical Students for Educational Purposes: A Meta-analysis and Systematic Review," North Am. J. Med. Sci., vol. 8, no. 7, pp. 268-278, Jul. 2016.

[16] S. Pinilla et al., "Undergraduate Medical Students Using Facebook as a Peer-Mentoring Platform: A Mixed-Methods Study," JMIR Med. Educ., vol. 1, no. 2, p. e12, Oct. 2015.

[17] A. K. Alsuraihi, A. S. Almaqati, S. A. Abughanim, and N. A. Jastaniah, "Use of social media in education among medical students in Saudi Arabia," Korean J. Med. Educ., vol. 28, no. 4, pp. 343-354, Dec. 2016.

[18] J. M. Bernhardt, J. Alber, and R. S. Gold, "A social media primer for professionals: digital dos and don'ts," Health Promot. Pract., vol. 15, no. 2, pp. 168-172, Mar. 2014.

[19] B. K. Park and C. Calamaro, "A systematic review of social networking sites: innovative platforms for health research targeting adolescents and young adults," J. Nurs. Scholarsh. Off. Publ. Sigma Theta Tau Int. Honor Soc. Nurs. Sigma Theta Tau, vol. 45, no. 3, pp. 256-264, Sep. 2013.

[20] M. P. Hamm, J. Shulhan, G. Williams, A. Milne, S. D. Scott, and L. Hartling, "A systematic review of the use and effectiveness of social media in child health," BMC Pediatr., vol. 14, p. 138, 2014.

[21] G. E. Brisson, M. J. Fisher, M. W. LaBelle, and S. E. Kozmic, "Defining a mismatch: differences in usage of social networking sites between medical students and the faculty who teach them," Teach. Learn. Med., vol. 27, no. 2, pp. 208-214, 2015.

[22] D. R. George and M. J. Green, "Beyond good and evil: exploring medical trainee use of social media," Teach. Learn. Med., vol. 24, no. 2, pp. 155-157, 2012.

[23] D. Patel and D. Jermacane, "Social media in travel medicine: a review," Travel Med. Infect. Dis., vol. 13, no. 2, pp. 135-142, Apr. 2015.

[24] K. N. Nason, H. Byrne, G. J. Nason, and B. O'Connell, "An assessment of professionalism on students' Facebook profiles," Eur. J. Dent. Educ. Off. J. Assoc. Dent. Educ. Eur., Oct. 2016.

[25] J. M. Bernhardt, J. Alber, and R. S. Gold, "A social media primer for professionals: digital dos and don'ts," Health Promot. Pract., vol. 15, no. 2, pp. 168-172, Mar. 2014.

[26] M. Camacho, J. M. Wei, and E. T. Chang, "Is It Inappropriate for Attendings and Residents to be Friends on Facebook and Other Social Media Accounts?," J. Grad. Med. Educ., vol. 8, no. 4, p. 624, Oct. 2016.

[27] E. A. Kitsis et al., "Who's misbehaving? Perceptions of unprofessional social media use by medical students and faculty," BMC Med. Educ., vol. 16, p. 67, 2016.

[28] S. Gupta, S. Singh, and U. Dhaliwal, "Visible Facebook profiles and e-professionalism in undergraduate medical students in India," J. Educ. Eval. Health Prof., vol. 12, p. 50, 2015.

[29] J. G. Boyle, J. M. Cullen, S. Sneddon, N. Sartania, and M. Shepherd, "Using Facebook as a platform for self-regulated curriculum evaluation and feedback for medical students," Med. Teach., vol. 38, no. 9, pp. 959-960, Sep. 2016.

[30] G. E. Brisson, M. J. Fisher, M. W. LaBelle, and S. E. Kozmic, "Defining a Mismatch: Differences in Usage of Social Networking Sites Between Medical Students and the Faculty Who Teach Them," Teach. Learn. Med., vol. 27, no. 2, pp. 208-214, Apr. 2015. 